ARAÚJO, A.P.; NEGREIROS, M.Z.; LEITÃO, M.M.V.B.R.; PEDROSA, J.F.; BEZERRA NETO, F.; ESPÍNOLA SOBRINHO, J.; FERREIRA, R.L.F.; NOGUEIRA, I. C. C. Rendimento de melão amarelo cultivado em diferentes tipos de cobertura do solo e métodos de plantio. Horticultura Brasileira, Brasília, v. 21, n. 1, p. 123-126, março 2003.

\title{
Rendimento de melão amarelo cultivado em diferentes tipos de cobertu- ra do solo e métodos de plantio ${ }^{1}$
}

\author{
Antônio de P. Araújo ${ }^{2}$; Maria Z. de Negreiros²; Mário de M. V. B. R. Leitão ${ }^{3}$; Josué F. Pedrosa ${ }^{4}$; Francisco \\ Bezerra Neto ${ }^{2}$; José Espínola Sobrinho²; Regina L. F. Ferreira²; Isení Carlos C. Nogueira. \\ ${ }^{2}$ ESAM, C. Postal 137, 59.625-900 Mossoró-RN.; ${ }^{3} \mathrm{UFPB}, 58.109-970$ Campina Grande-PB; ${ }^{4} \mathrm{UERN}$, Mossoró-RN; E-mail: \\ zuleide@esam.br
}

\begin{abstract}
RESUMO
Avaliou-se o rendimento de melão amarelo em diferentes tipos de cobertura do solo e métodos de plantio, em experimento na Fazenda Água Branca (FRUNORTE), no município de CarnaubaisRN. O delineamento experimental foi o de blocos casualizados, em esquema de parcelas subdivididas, com quatro repetições. As parcelas foram constituídas pelas coberturas do solo [palha de carnaúba, filme de polietileno preto, filme de polietileno dupla face (prateado e preto) e solo descoberto] e as subparcelas pelos métodos de plantio (semeadura direta e transplante direto com produção de mudas em tubetes de $125 \mathrm{~mL}$, copos plásticos de $180 \mathrm{~mL}$ e bandejas de 72 células). As características avaliadas foram peso médio de frutos comerciáveis, número de frutos comerciáveis, produtividade de frutos comerciáveis e não comerciáveis e classificação dos frutos. As coberturas do solo e os métodos de plantio não apresentaram efeito significativo para número, peso médio e produtividade de frutos comerciáveis e não comerciáveis. Em relação ao mercado externo, as coberturas do solo proporcionaram maior concentração de frutos tipos 5 e 6, enquanto que para o mercado interno, registrou-se maior percentagem de frutos dos tipos 5 a 8 .
\end{abstract}

Palavras-chave: Cucumis melo, produção, filmes de polietileno, classificação de frutos.

\begin{abstract}
Yellow melon yield in different mulching and planting methods

Yield of yellow melon in different mulching and planting methods was evaluated through an experiment carried out in Carnaubais, Rio Grande do Norte State, Brazil. The experimental design was of randomized complete blocks with four replications and split plot. Mulching treatments (sliced carnauba dried leaves, black polyethylene film, aluminum polyethylene film and unmulched soil) were set in the plots and the plantation methods (direct sowing and direct transplanting) were set in the subplots. Seedlings were produced in 72-celled trays, $180 \mathrm{ml}$ plastic containers, and $125 \mathrm{ml}$ tubets. Fruit average weight, number and yield of marketable and notmarketable fruits and fruit classification, were evalueted. Mulching treatments and plantation methods did not affect the number of fruits, average weight and yield. For external market, mulching treatments produced fruits of type 5 and 6 and for internal market of types $5-8$.
\end{abstract}

Keywords: Cucumis melo, yield, polyethylene films, fruit classification.

\section{(Recebido para publicação em 18 de abril de 2001 e aceito em 20 de dezembro de 2002)}

\begin{abstract}
A produção de melão no Brasil tem aumentado substancialmente nos últimos anos, sendo a Região Nordeste a principal produtora, contribuindo com mais de $90 \%$ da produção nacional. Dentre os estados produtores destacamse RN, CE, BA e PE. O RN é o maior produtor brasileiro, sobressaindo-se em 1996, com $60 \%$ da produção (AGRIANUAL, 2000).
\end{abstract}

A expansão da cultura do melão no RN nos últimos anos, se deve à atuação das grandes empresas que destinam a sua produção para exportação. Entretanto, pouco esforço tem sido dedicado ao desenvolvimento de tecnologias que visem melhorar o rendimento, a qualidade do melão, e o custo de pro- dução da cultura. Nesse contexto, o estudo de fatores de produção, tais como, adubação, irrigação, cobertura do solo, métodos de plantio e outras práticas culturais, tornam-se necessários para aumentar o rendimento e qualidade do melão produzido.

No caso específico da cobertura do solo, tem sido verificado, em diversos trabalhos, que os resultados variam de acordo com os materiais de cobertura empregados, tipos de melão e com as condições edafoclimáticas em que a cultura está sendo conduzida (Montsenbocker \& Bonanno, 1989, Orozco-Santos et al.,1995; Bradenberger \& Wiendenfeld, 1997; Martins et al., 1998).
Orozco-Santos et al. (1995) verificaram um aumento expressivo na produção total de melão cultivado em plástico transparente $(31,1 \mathrm{t} / \mathrm{ha})$ em relação ao solo descoberto $(6,6 \mathrm{t} / \mathrm{ha})$. Utilizando plástico preto, transparente e solo descoberto, Battikhi \& Ghawi (1987) também observaram efeitos significativos para os tratamentos, que apresentaram produção de $28,7 \mathrm{t} / \mathrm{ha}, 14,2 \mathrm{t} / \mathrm{ha} \mathrm{e}$ 6,0 t/ha, respectivamente. Bradenberger $\&$ Wiendenfeld (1997), verificaram aumento na produção de melão, em média, de $42 \%$ em 1994 e $27 \%$ no ano de 1995, com a utilização da cobertura do solo em relação ao solo descoberto. Além do aumento de produção e peso médio dos frutos, observaram aumento

${ }^{1}$ Parte da dissertação de mestrado do primeiro autor apresentada à ESAM, Mossoró-RN 
nos teores de sólidos solúveis de $0,6 \%$ para os tratamentos com filmes em relação ao solo descoberto. Em 1985, utilizando diferentes tipos de poliéster, polietileno transparente e solo descoberto no cultivo do melão, Montsenbocker \& Bonanno (1989) não verificaram efeito significativo dos tratamentos no peso médio dos frutos e produção. Entretanto, em 1986, observaram redução na produção de frutos comercializáveis no tratamento com filme perfurado em relação ao poliéster fiado. Os autores atribuíram esta redução ao aumento da temperatura do solo. Martins et al., (1998), também não observaram efeito da cobertura do solo (sem cobertura e com filme polietileno preto) sobre o rendimento, número de frutos por planta $\mathrm{e}$ peso médio de frutos de melão das cultivares Amarelo (tipo Espanhol) e Melina (tipo Gália). Com relação ao teor de sólidos solúveis verificaram que para a cultivar Amarelo, o tratamento com cobertura do solo proporcionou valores em grau Brix $\left(13^{\circ}\right)$ superiores aos obtidos com solo descoberto $\left(11,9^{\circ}\right)$. Para a cultivar Melina, o teor de Brix foi ligeiramente superior para o solo descoberto $\left(9,3^{\circ}\right)$ em relação ao solo com cobertura $\left(8,9^{\circ}\right)$.

Com relação aos métodos de plantio, o meloeiro é tradicionalmente plantado por semeadura direta, aumentando substancialmente os custos de produção, principalmente quando se utiliza sementes híbridas, devido ao custo elevado, tornando-se muitas vezes antieconômico. O uso do método de transplante direto, com produção de mudas em recipientes, constitui-se uma alternativa para a redução dos custos com sementes, uma vez que apresenta maior economia de sementes quando comparado com o método de semeadura direta.

A semeadura em recipientes e posterior transplante é um método de plantio que tem sido raramente utilizado, limitando-se atualmente ao plantio e replantio de pequenas áreas, no caso dos híbridos de preços elevados. Diversos recipientes são utilizados para a semeadura do melão, como copos de jornal, copos de iogurte, saquinhos de polietileno, bandejas ou assemelhados. O ideal é que esses recipientes tenham um volume de 50 a $80 \mathrm{ml}$, o que permite um bom desenvolvimento do sistema radicular (Pedrosa, 1997). Correia (1996), avaliando o efeito de quatro tipos de recipientes na formação de mudas, produção e qualidade de frutos de melão, verificou que o vigor das mudas foi influenciado pelo tipo de recipiente. Com relação à produção total de frutos, a semeadura direta proporcionou aumento de $13,5 \%$ e quanto ao formato e qualidade dos frutos não se verificou efeito dos recipientes na formação das mudas.

Na Flórida, Maynard et al. (1996) testando recipientes de diferentes volumes $\left(7 ; 22 ; 25 ; 36 ; 50 ; 70\right.$ e $\left.100 \mathrm{~cm}^{3}\right)$ na produção de mudas das cultivares Mission e Superstar, tipo Cantaloupe, observaram interação significativa entre cultivar e volume de células. O número de frutos totais e produtividade total aumentaram em função do aumento do volume de células. O relacionamento linear foi mais forte para a cultivar Mission do que para a Superstar. Segundo os autores, estes resultados são consistentes com os efeitos do tamanho de células reportados para outras culturas, incluindo melancia, onde as produções são variáveis e dependem, em parte, da cultivar.

O presente trabalho teve como objetivo avaliar o rendimento e a classificação de frutos para exportação e mercado interno de melão amarelo cultivado em diferentes tipos de cobertura do solo e métodos de plantio.

\section{MATERIAL E MÉTODOS}

O experimento foi desenvolvido no município de Carnaubais (RN) em uma das áreas produtoras de melão da Fazenda Água Branca (FRUNORTE), em um solo classificado como Luvissolo Crônico (Alisol). As análises químicas, feitas em amostras retiradas à profundidade de 0 - $20 \mathrm{~cm}$, da área experimental, revelaram: $\mathrm{pH}$ (água 1:2,5) $=6,7$; M.O. $=1 \% ; \mathrm{P}($ resina $)=34 \mathrm{mg} / \mathrm{cm}^{3}$; $\mathrm{S}=56 \mathrm{meq} / 100 \mathrm{~cm}^{3} ; \mathrm{Ca}=3,51 \mathrm{meq} /$ $100 \mathrm{~cm}^{3} ; \mathrm{Mg}=0,82 \mathrm{meq} / 100 \mathrm{~cm}^{3} ; \mathrm{K}=$ $0,33 \mathrm{meq} / 100 \mathrm{~cm}^{3} ; \mathrm{Na}=0,14 \mathrm{meq} / 100$ $\mathrm{cm}^{3} ; \mathrm{Al}=0,00 \mathrm{meq} / 100 \mathrm{~cm}^{3} \mathrm{e} \mathrm{H}+\mathrm{Al}=$ $0,22 \mathrm{meq} / 100 \mathrm{~cm}^{3} ; \mathrm{Cu}=0,20 ; \mathrm{Zn}=1,2$; $\mathrm{Fe}=8 ; \mathrm{Mn}=76$ e $\mathrm{B}=0,6 \mathrm{ppm}$.
O delineamento experimental utilizado foi o de blocos casualizados, em esquema de parcelas subdivididas, com quatro repetições. As parcelas foram constituídas pelas coberturas do solo [palha de carnaúba triturada, filme de polietileno preto, filme de polietileno dupla face (prateado e preto) e solo descoberto] e as subparcelas constaram dos métodos de plantio (direto e semeiotransplante com produção de mudas em bandejas de poliestireno com 72 células, copos plásticos de $180 \mathrm{~mL}$ e tubetes de polietileno de $125 \mathrm{~mL}$ ). Cada subparcela constou de três fileiras de 5 m de comprimento, com duas plantas por cova espaçada de $2,0 \times 0,5 \mathrm{~m}$. A área útil por subparcela foi de $8,0 \mathrm{~m}^{2}$, correspondendo a 16 plantas da fileira intermediária, sendo que as plantas das extremidades foram consideradas como bordaduras. Utilizou-se o híbrido Gold Mine, em razão de sua ampla aceitação pelos produtores da região.

O preparo do solo constou da confecção de canteiros, espaçados de 2,0 m entre linhas, sendo em seguida realizada a colocação da palha de carnaúba triturada e dos filmes de polietileno preto e dupla-face (prateado e preto), nos respectivos tratamentos. Nos filmes de polietileno a abertura dos orifícios de plantio foi realizada utilizando-se um vazador de 2,5 polegadas de diâmetro.

Em 08/09/98, foi realizada a semeadura colocando-se duas sementes por recipiente em bandejas de poliestireno com 72 células, copos plásticos de 180 $\mathrm{mL}$ e tubetes de polietileno $125 \mathrm{~mL}$. O substrato comercial empregado foi definido pelo fabricante como uma mistura de duas partes de humus para uma de vermiculita (Plantmax Frutos). No mesmo dia, foi efetuado o plantio direto utilizando-se três a quatro sementes por cova, seguido de desbaste quando as plantas apresentavam duas folhas definitivas, deixando-se duas plantas por cova. Oito dias após a semeadura efetuou-se o transplante das mudas para o local definitivo.

A adubação foi efetuada em fertirrigação, utilizando-se $120 \mathrm{~kg}$ de N/ ha, $297 \mathrm{~kg}$ de $\mathrm{K}_{2} \mathrm{O} / \mathrm{ha}, 95 \mathrm{~kg}$ de $\mathrm{P}_{2} \mathrm{O}_{5} / \mathrm{ha}$ e $86 \mathrm{~kg} \mathrm{de} \mathrm{Ca} / \mathrm{ha}$. Irrigação e controle fitossanitário foram realizados de acordo com as necessidades da cultura. Fo- 
Tabela 1. Peso médio de frutos comerciáveis (PMFC), número de frutos comerciáveis (NFC), produtividade de frutos comerciáveis (PFC) e produtividade de frutos não comerciáveis (PFNC). Carnaubais (RN), ESAM, 1998.

\begin{tabular}{lcccc}
\hline \multicolumn{1}{c}{ Tipos de cobertura do solo } & PMFC (kg) & NFC (frutos/ha) & PFC (t/ha) & PFNC (t/ha) \\
\hline Polietileno dupla-face (prateado) & 2,0 & 18.000 & 35,8 & 6,9 \\
Polietileno Preto & 2,0 & 18.813 & 36,8 & 7,7 \\
Palha de carnaúba & 2,0 & 21.375 & 36,5 & 8,0 \\
Solo descoberto & 2,0 & 20.125 & 38,3 & 8,9 \\
\hline Métodos de plantio : & \multicolumn{5}{c}{} & 39,3 & 8,8 \\
\hline Plantio direto & 1,9 & 20.563 & 33,6 & 8,3 \\
Tubete 125 ml & 1,9 & 18.250 & 41,3 & 7,3 \\
Copo plástico 180 ml & 2,0 & 21.000 & 32,6 & 7,2 \\
Bandeja 72 células & 1,9 & 18.500 & &
\end{tabular}

ram realizadas três colheitas (a primeira aos 62 dias após o plantio e as demais em intervalos de sete dias). O critério para colheita adotado foi a coloração do fruto, ou seja, quando os mesmos apresentavam-se totalmente amarelos.

Avaliou-se o peso médio de frutos comerciáveis $(\mathrm{kg})$, número de frutos comerciáveis ( $\mathrm{t} / \mathrm{ha}$ ) e produtividade de frutos comerciáveis e não comerciáveis (t/ha). Ainda, a classificação dos frutos foi realizada de acordo com o tipo (5 a 12 frutos por caixa), padronizados pela empresa para mercados interno e externo, em caixas de papelão $52 \times 32 \times 17,5$ cm, 49,5 x 33,0 x 16,0 cm com capacidade para $13 \mathrm{~kg}$ e $10 \mathrm{~kg}$, respectivamente. Frutos foram considerados não comerciáveis quando não se enquadravam no padrão de qualidade para encaixamento; entretanto, parte deles pode ser comercializada em feiras livres ou supermercados.

As análises de variância foram realizadas através do aplicativo do software SPSSPC (Norusis, 1990). Para comparação das médias dos tratamentos, foi utilizado o teste Tukey ao nível de 5\% de probabilidade (Gomes, 1990).

\section{RESULTADOS E DISCUSSÃO}

Não houve interação significativa entre os tipos de cobertura do solo e métodos de plantio para as características peso médio de frutos comerciáveis, número de frutos comerciáveis, produtividade de frutos comerciáveis e não comerciáveis.

Observou-se que não houve influência da cobertura do solo no peso médio de frutos, número de frutos e produtividade de frutos comerciáveis (Tabela 1). A elevada intensidade luminosa da região pode ter contribuído para uma intensa atividade fotossintética da planta, ocorrendo assim compensação no número de frutos/ha. Segundo Pedrosa (1997) a produtividade de uma cultura é função do potencial genético do material, tratos culturais e das condições edafoclimáticas, principalmente da luminosidade, que muitas vezes pode compensar algumas condições adversas, devido ao aumento da capacidade fotossintética, implicando num aumento de produtividade. Para cultivo de melão em estufa Martins et al. (1998), também não observaram diferença significativa para estas características, com uso de cobertura de solo com filme preto. Os autores atribuíram estes resultados às condições edafoclimáticas, principalmente, a temperatura do solo, uma vez que tem-se observado que o aquecimento excessivo do solo devido ao uso da cobertura contribui na redução da capacidade produtiva da cultura. Entretanto, Orozco-Santos et al. (1995), Bradenberger \& Wiendenfeld (1997) e Battikhi \& Ghawi (1987), observaram aumento na produtividade de frutos de melão com a utilização da cobertura do solo com filme preto.

Os pesos médios de frutos comerciáveis obtidos neste experimento (Tabela 1), foram superiores aos encontrados por Grangeiro et al. (1999), onde foram observados valores variando de 1,3 a 1,6 kg, superando até mesmo o peso médio deste híbrido, que é de $1,8 \mathrm{~kg}$ (Pedrosa, 1997). O peso mé- dio de frutos é uma característica inerente a cultivar/híbrido, entretanto, pode sofrer influência dos tratos culturais, principalmente da sanidade da cultura. A redução na área foliar implica em redução da capacidade fotossintética da planta e consequentemente, menor quantidade de carboidratos para os frutos. Widederrs \& Price (1989) observaram que o crescimento do fruto é altamente competitivo com o crescimento vegetativo e a assimilação de carbono é acelerada pelas folhas, em resposta à grande demanda imposta pelo crescimento desse órgão.

Quanto aos métodos de plantio, observou-se não haver influência sobre as características avaliadas (Tabela 1). Entretanto, Correia (1996) verificou que o melão amarelo 'Gold Mine' plantado por meio de semeadura direta proporcionou aumento de $13,5 \%$ na produção total de frutos, em relação ao melão cultivado a partir de mudas transplantadas. Por outro lado, Maynard et al. (1996) observaram interação significativa entre cultivares e tipos de recipientes. $\mathrm{O}$ número de frutos totais e produtividade total das cultivares Mission e Superstar, tipo Cantaloupe, aumentaram em função do aumento do volume dos recipientes. O relacionamento linear foi mais forte para a cultivar Mission do que para a Superstar. Segundo os autores, estes resultados são consistentes com os efeitos do tamanho de recipientes reportados para outras culturas, incluindo melancia, onde as produções são variáveis e dependem, em parte, da cultivar.

A classificação dos frutos é de fundamental importância na 
Tabela 2. Classificação percentual dos frutos tipo exportação e tipo mercado interno de acordo com o tamanho, nas diferentes coberturas do solo e métodos de plantio. Carnaubais (RN), ESAM, 1998.

\begin{tabular}{|c|c|c|c|c|c|c|c|c|c|c|c|c|c|c|c|c|}
\hline \multirow{2}{*}{$\begin{array}{c}\text { Tipos de } \\
\text { cobertura do } \\
\text { solo }\end{array}$} & \multirow{2}{*}{$\begin{array}{c}\text { Métodos de } \\
\text { plantio }\end{array}$} & \multicolumn{7}{|c|}{ Tipo exportação (TE) } & \multicolumn{8}{|c|}{ Tipo mercado interno (TMI) } \\
\hline & & TE & 05 & 06 & 07 & 08 & 09 & 10 & TMI & 05 & 06 & 07 & 08 & 09 & 10 & 11 \\
\hline \multirow{4}{*}{$\begin{array}{l}\text { Solo } \\
\text { descoberto }\end{array}$} & Plantio direto & 32,65 & 46,87 & 25,00 & 15,63 & 12,50 & & & 67,35 & 15,15 & 28,79 & 25,75 & 15,15 & 7,58 & 7,58 & \\
\hline & Tubetes $125 \mathrm{ml}$ & 29,86 & 55,00 & 40,00 & 5,00 & & & & 70,14 & 6,38 & 29,79 & 27,66 & 19,15 & 8,51 & 6,38 & 2,13 \\
\hline & Copos $180 \mathrm{ml}$ & 31,65 & 44,00 & 48,00 & 4,00 & 4,00 & & & 68,35 & 3,70 & 33,40 & 37,00 & 11,10 & 11,10 & 1,85 & 1,85 \\
\hline & $\begin{array}{l}\text { Bandeja } 72 \\
\text { células }\end{array}$ & 33.78 & 61.54 & 30,76 & 3,85 & 3,85 & & & 66,22 & 10,2 & 22,50 & 36,70 & 16,30 & 6,12 & 6,12 & 2,06 \\
\hline \multirow{4}{*}{$\begin{array}{l}\text { Polietileno } \\
\text { preto }\end{array}$} & Plantio direto & 25,61 & 47,6 & 52,40 & & & & & 74,39 & 19,67 & 22,95 & 21,31 & 21,31 & 6,56 & 4,92 & 3,28 \\
\hline & Tubetes $125 \mathrm{ml}$ & 31,17 & 50,0 & 45,83 & 4,17 & & & & 68,83 & 5,66 & 26,40 & 43,40 & 18,87 & 5,66 & & \\
\hline & Copos $180 \mathrm{ml}$ & 28,57 & 42,30 & 57,70 & & & & & 71,43 & 13,85 & 38,46 & 18,46 & 10,77 & 7,69 & 7,69 & 3,08 \\
\hline & $\begin{array}{l}\text { Bandeja } 72 \\
\text { células }\end{array}$ & 34,62 & 83,30 & 16,70 & & & & & 65,38 & 8,82 & 35,29 & 23,53 & 14,71 & 11,77 & 5,88 & \\
\hline \multirow{4}{*}{$\begin{array}{l}\text { Polietileno } \\
\text { dupla-face }\end{array}$} & Plantio direto & 38,03 & 44,40 & 55,60 & & & & & 61,97 & 18,19 & 36,36 & 9,09 & 9,09 & 20,45 & 6,82 & \\
\hline & Tubetes $125 \mathrm{ml}$ & 32,73 & 55,60 & 44,40 & & & & & 67,27 & 10,82 & 27,02 & 27,02 & 27,02 & 8,12 & & \\
\hline & Copos $180 \mathrm{ml}$ & 26,83 & 63,60 & 36,40 & & & & & 73,17 & 13,33 & 36,67 & 18,33 & 13,33 & 11,67 & 5,00 & 1,67 \\
\hline & $\begin{array}{l}\text { Bandeja } 72 \\
\text { células }\end{array}$ & 28,75 & 52,20 & 47,80 & & & & & 71,25 & 8,77 & 28,10 & 26,30 & 7,02 & 22,8 & 5,26 & 1,75 \\
\hline \multirow{4}{*}{$\begin{array}{l}\text { Palha de } \\
\text { carnaúba }\end{array}$} & Plantio direto & 52,56 & 51,22 & 36,59 & 7,32 & 4,87 & & & 47,44 & 5,41 & 27,01 & 45,95 & 5,41 & 5,41 & 10,81 & \\
\hline & Tubetes $125 \mathrm{ml}$ & 36,14 & 50,00 & 50,00 & & & & & 63,86 & 18,87 & 16,98 & 39,62 & 11.32 & 11,32 & & 1,89 \\
\hline & Copos $180 \mathrm{ml}$ & 31,76 & 40,74 & 48,15 & 7,41 & 3,70 & & & 68,24 & & 29,31 & 22,41 & 29,31 & 1,73 & 17,24 & \\
\hline & $\begin{array}{l}\text { Bandeja } 72 \\
\text { células }\end{array}$ & 40,70 & 48,57 & 20,00 & 14,29 & 2,86 & 8,57 & 5,71 & 59,30 & 13,73 & 29,41 & 33,33 & 5,88 & 9,81 & 5,88 & 1,96 \\
\hline
\end{tabular}

comercialização, uma vez que a boa apresentação do produto proporciona maior atração aos consumidores. Verificou-se que independentemente do tipo de cobertura do solo e métodos de plantio, houve maior percentagem de frutos tipo mercado interno (TMI) em relação ao tipo exportação (TE) (Tabela 2). Provavelmente, um atraso na viragem dos frutos, prática cultural, que consiste em girar o fruto em aproximadamente $45^{\circ}$, e a incidência de ventos fortes tenham contribuído para a redução no percentual de frutos tipo exportação, devido à presença da mancha de encosto e das injúrias causadas pelo atrito das folhas com os frutos.

Em termos de mercado externo, observou-se maior concentração de frutos tipos 5 e 6, enquanto dos tipos 5, 6, 7 e 8 para o mercado interno (Tabela 2). Dependendo da preferência do mercado, alguns cuidados devem ser tomados quando da utilização da cobertura do solo para reduzir o tamanho dos frutos, como manejo nutricional e aumento da população de plantas. Grangeiro et al. (1999), obtiveram maior percentagem de frutos de categorias menores, quando aumentaram a densidade de plantio de melão.
Embora não se tenha constatado efeito diferenciado entre as coberturas do solo com relação ao rendimento de melão, esta técnica de cultivo se reveste de grande importância para os produtores da região, considerando que pode reduzir os custos de produção no controle de doenças, pragas (Orozco-Santos et al.,1995) e de plantas invasoras (Zapata, et al., 1989), além de diminuir a quantidade de água a ser aplicada à cultura (Martins et al., 1998).

\section{LITERATURA CITADA}

AGRIANUAL 2000, Melão: Produção Brasileira. São Paulo: São Paulo: FNP consultoria, 2000. p. 114. BATTIKHI, A.M.; GHAWI, I. Muskmelon production under mulch and trickle irrigation in the Jordan Valley. HortSience, v. 22, n. 4, p. 578581, 1987.

BRADENBERG, L.; WIENDEFELD, B. Physical characteristics of mulches and their impact on crop response and profitability in muskmelon production. HortTechnology, v. 7, n. 2, p. 165-169, 1997.

COOREIA, P.S.F. Períodos de permanência e tipos de recipientes na formação de mudas, produção e qualidade do melão 'Gold mine'. Mossoró: ESAM, 1996, 62 p. (Tese mestrado)

GOMES, P. F. Curso de Estatística Experimental. Piracicaba: Francisco Pimentel Gomes, 2000, $470 \mathrm{p}$.
GRANGEIRO, L.C.; PEDROSA, J.F.; BEZERRA NETO, F; NEGREIROS, M. Qualidade de híbridos de melão em diferentes densidades de plantio. Horticultura Brasileira, Brasília, v. 17, n. 2, p. 110-113, 1999.

MARTINS, S.R.; PEIL, R.M.; SCHWENGBER, J.E.; ASSIS, F.N.; MENDES, M.E.G. Produção de melão em função de diferentes sistemas de condução de plantas em ambiente protegido. Horticultura Brasileira, Brasília, v. 16, n. 1, p. 24-30, 1998.

MAYNARD, E.T.; VAVRINA, C.S.; SCOTT, W.D. Containized muskmelon transplants: cell volume effects on pretransplant development and subsequent yield. HortScience, v. 31, n. 1, p. 5861, 1996.

MONTSENBOCKER, C.E.; BONANNO, A.R. Row cover effects on air and soil temperatures and yield of muskmelon. HortScience, v. 24, n. 4, p. 601-603, 1989.

NORUSIS, M.J. SPSS statistics. Illinois, SPSS Inc., $1990,330 \mathrm{p}$.

OROZCO-SANTOS, M.; PREZE-ZAMORA, O.; LOPEZ-ARRIAGA, O. Effect of transparent mulch on insect populations, virus diseases, soil temperature, and yield of cantaloup in the a tropical region. New Zealand Journal of Crop and Horticultural Science, v. 23, p. 199-204, 1995. PEDROSA, J.F. Cultura do melão. Mossoró:ESAM, 1997. 50 p. (Apostila).

WINDERS, I.E. ; PRICE, H.C. Effects of plant density on growth and biomass partitioning in pickling cucumbers. Journal American Society Horticultural Science, v. 114, n. 5, p. 751-755, 1989. ZAPATA, M.; CABREIRA, P.; BAÑON, S.; ROTH, P. El melon. Madrid: Mundi-Prensa, 1989. $174 \mathrm{p}$ 